\title{
Investigation on the Effects of Recycling and Injection Parameters on Gloss Properties of Smooth Polypropylene Parts
}

\author{
Zaineb Baccouch ${ }^{1(凶)}$, Souad Mbarek $^{2}$, Didier Perrin ${ }^{3}$, \\ Olivier Eterradossi ${ }^{3}$, Bernard Monasse ${ }^{4}$, Helene Garay ${ }^{3}$, and Jean- \\ Christophe Quantin ${ }^{3}$ \\ ${ }^{1}$ Laboratoire des Systems Electromécaniques, Ecole Nationale d'Ingénieurs de \\ Sfax, Sfax, Tunisia \\ baccouch.zaineb@gmail.com \\ ${ }^{2}$ Laboratoire de Mécanique de Sousse (LMS), LR11ES36, Ecole Nationale \\ d'Ingénieurs de Sousse, Sousse, Tunisia \\ ${ }^{3}$ Centre des Matériaux des Mines d'Alès (C2MA), Ecole des Mines d'Alès, \\ Alès, France \\ ${ }^{4}$ Centre de Mise en Forme des Matériaux (CEMEF), Ecole des mines de Paris, \\ Paris, France
}

\begin{abstract}
The aim of this paper is to investigate the optical properties of the recycled polymer during numerous internal reprocess using experimental design. The process conditions (material temperature, mold temperature, injection rate) and recycling on the gloss and colorimetric properties of polypropylene containing $2 \mathrm{wt} \%$ of pigment was studied. Several injection parameters and cycles numbers must be tested. One most limit for this kind of study is the large number of experiments that requires longtime and significant investments. The idea is to vary three injection parameters (Temperature of material, Temperature of the mold, injection rate) for five injection cycles using statistical approach. The three variables (materiel temperature, mold temperature and injection flow) were investigated at three industrial used levels. The number of recycling varies from cycle 0 to cycle 4 at five levels. The complete matrix for screening was designed using D-optimal quadratic design. The experimental design was generated with the statistical software MODDE 10.1-Umetrics. A set of 45 experiments was carried out to determine the influence of injection parameters and recycling on the appearance properties of samples. The statistical software package Nemrodw ${ }^{\circledR}$ version 2007, LPRAI (Marseille, France) was used to analyze the experimental design.
\end{abstract}

Keywords: Recycling $\cdot$ Gloss properties $\cdot$ PP $\cdot$ Experimental design

\section{Introduction}

Appearance properties of objects are one of the most challenges of nowadays industries, to keep a place in a diversified market full of competition. To this commitment of quality was also added the necessity of recycling, especially for the plastics industry. In 
a commercial production process, it is important to get rid of waste product. These are usually recycled to improve cost performance. However, this recycling process often brings unfavorable effects, e.g., an increase in appearance properties. To achieve this compromise between recycling and good esthetic of produces, studies on the effect of recycling on the appearance properties of polymers are needed. The effect of recycling on optical properties of polymer films has been few analyzed in the literature $[1,2]$ but no study has been done on the effect of recycling on the appearance properties of injected parts. Among other plastics, polypropylene (PP) is a commodity polymer product and used in large quantities for many applications. The main reasons for the success of PP are its quite good price/performance ratio, its excellent mechanical properties, and suitable optical characteristics [3]. The huge consumption of this polymer makes its recycling strategically very important for the environmental policy of industry [4]. On the other hand, appearance properties of polymer products are mostly determined by the processing parameters. A low cavity surface temperature makes the polymer melt freeze prematurely and consequently a frozen layer will be formed during filling process at the interface between the hot polymer melt and the cold mould cavity, which leads to a series of defects of the final moulded parts, such as flow mark [5, 6] weld mark [7, 8], swirl mark [9], roughness [10], low gloss [11], and low replication accuracy [12]. Zhang et al [13] showed that surface quality of plastic parts can be improved significantly by increasing mold cavity temperature. The gloss of both $\mathrm{ABS} / \mathrm{PMMA}$ and $\mathrm{ABS} / \mathrm{PMMA} /$ nano- $\mathrm{CaCO}_{3}$ gradually increase with the increase of mold cavity temperature. The process conditions had a strong influence on the gloss development and on the color of pigmented PP. A better replication of the mold texture can be achieved at a lower melt viscosity at higher shear rates and higher mold temperatures. This gives a higher gloss in smooth regions. The gloss had a significant effect on the color: all the factors that contributed to an increase in gloss showed concomitant effects of increasing the color coordinate $b^{*}$ and of decreasing the lightness $\mathrm{L}^{*}$. Studies were published showing that the processing parameters may affect the gloss of injection molded parts [14], the mold temperature commonly being considered the more important parameter to be controlled. It was clearly shown that the mold temperature is the more relevant parameter and that a clear interaction exists between that parameter and the holding pressure.

From a physical point of view, the two quantitative descriptors of appearance (gloss and color) are the consequences of complex psychophysical phenomena of visual perception related to a situation in which the light reflected from the surface of an opaque sample is either predominantly in the specular direction (gloss) or diffuse in all directions (color) [15]. The four variables that primarily affect the gloss are the surface topography (or texture) [16], the wavelength and angle of the incident light and the refractive index of the material [17], whereas the color depends on the illumination conditions, the observation angle, the optical characteristics of the material, the amount of the colorant present, the surface topography [18], and the gloss [19]. Work on polymeric surfaces has shown a decrease in gloss with increased roughness [20].

In this paper, we mainly focus on the effect of process conditions (material temperature, mold temperature, injection rate) and recycling on the gloss and colorimetric properties of polypropylene containing $2 \mathrm{wt} \%$ of pigment using statistical approach. 


\section{Materials and Techniques}

\subsection{Materials}

The PP homopolymer SABIC ${ }^{\circledR}$ PP 575P produced by SABIC Europe was used in the experiments. SABIC ${ }^{\circledR}$ PP 575P is an homopolymer for injection molding. A masterbatch supplied by Clariant was used to obtain a gray-beige complexion. The masterbatch was characterized with EDS analysis by scanning electron microscopy. The analyze show the presence of: $\mathrm{CaCO}_{3}$ (calcium carbonate), $\mathrm{TiO}_{2}$ (titanium dioxide) and $\mathrm{Sb}_{2} \mathrm{O}_{3}$ (Antimony trioxide). Blending of PP with $2 \mathrm{wt} \%$ of pigments (masterbatch) was performed in the PEP "plastics technical center" with a co-rotating intermeshing twinscrew extruder (Clextral EVOLUM HT 32, diameter $32 \mathrm{~mm}$, centerline distance $21 \mathrm{~mm}$ ) with a length to diameter ratio L/D 44. The screw profile is made of conveying and kneading elements, also using opposite pitch to ensure melting, mixing, shearing, and a good dispersion of the components. The extrusion process was carried out with a screw rotation speed of $350 \mathrm{rpm}$, at a temperature of $210{ }^{\circ} \mathrm{C}$ and a throughput of $30 \mathrm{~kg} \mathrm{~h}^{-1}$. The colored pellets were also injection-molded to obtain samples for study.

\subsection{Techniques}

Material processing: The mold was supplied by CFO company specialized on "Manufacturing Design Tools". The mold design was realized in C2MA to obtain samples of $100 \mathrm{~mm} \times 100 \mathrm{~mm}$ with a thickness of $2 \mathrm{~mm}$. the samples show two different faces, a polished mirror surface and a rough surface. All specimens were prepared on a Krauss Maffei KM50-180CX injection molding machine. The maximum clamping force is 50 tons. During experiment, corresponding to each set of experimental parameters, the 5 first injected samples are thrown away to ensure that the process was stable. PP was injected from zero to five steps of recycling. Samples are grinding with a Cutting Mill SM 300 to be reinjected.

Colorimetry: In a uniform color scale, the differences between points plotted in the color space correspond to visual differences between the colors plotted. The $\mathrm{L}^{*}$ axis is the light-dark axis, and thus gives a measure of the relative brightness of the sample ranging from total black $\left(\mathrm{L}^{*}=0\right)$ to the white $\left(\mathrm{L}^{*}=100\right)$. The $\mathrm{a}^{*}$ axis is the red-green axis (positive $a^{*}=$ red, negative $a^{*}=$ green), and the $b^{*}$ axis is the blueyellow axis (positive $b^{*}=$ yellow, negative $b^{*}=$ blue) [21] (Fig. 1).

Brightness: In terms of physical measurements, especially in the industrial field, gloss of materials is considered only at specular angles using a glossmeter [22]. Glossmeters are built to afford three specular geometries (Fig. 2). The geometry is chosen based on the gloss level observed, selecting the 20 specular reflection for high-gloss materials and 85 for quasi-matt samples, while 60 is used for samples with an intermediate, satin-like appearance.

Statistical approach: In a purpose of understanding the effect of injection parameters and recycling on the appearance properties of polymers, several injection parameters and cycles numbers must be tested. One main limit for this kind of study is the large number of experiments that requires longtime and significant investments. The idea is to vary three injection parameters temperature of material 


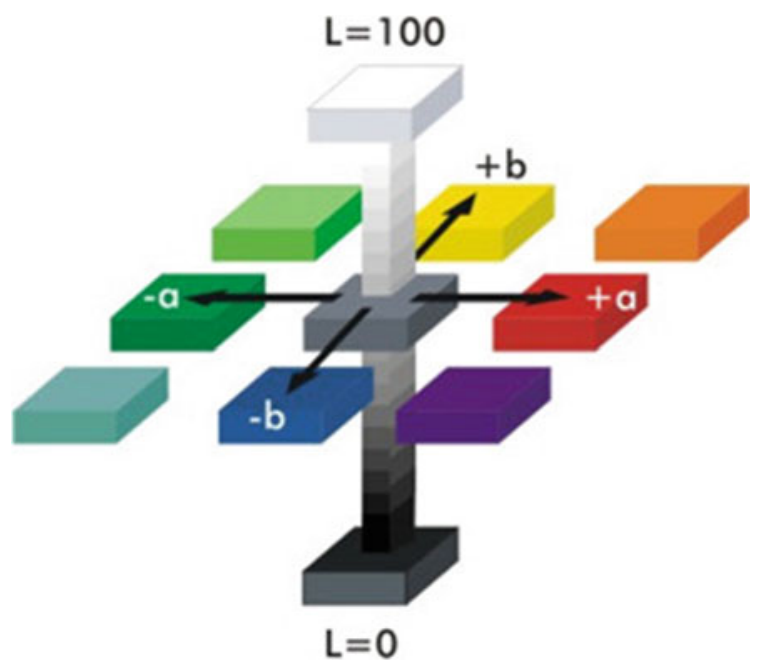

Fig. $1\left(L^{*}, a^{*}, b^{*}\right)$ representing color space

(a)

T material

220

240

260

$T$ mold

30

50

Injection rate

20

30

Cycles

cyele 0

cycle 1

cycle 2

cycle 3

cycle 4 (b)

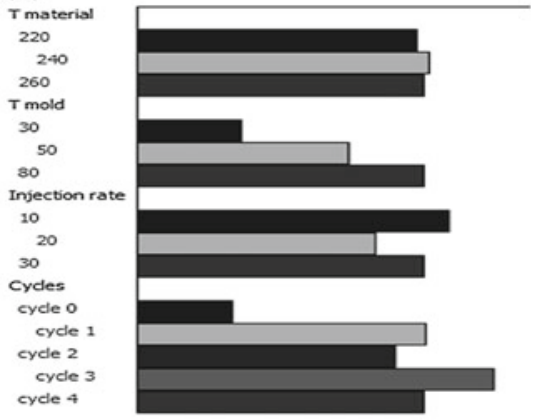

(c)

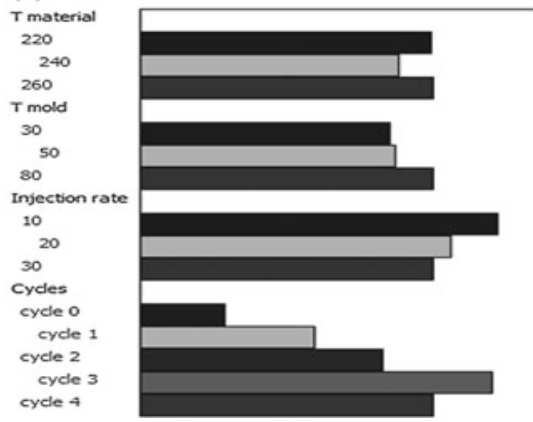

Fig. 2 Graphic representation of the difference in weight of the factors on total effect for the gloss response a R20, b R60, c R85 
(Tmaterial), Temperature of the mold (Tmold) and the injection rate for five injection cycles. The work material selected for the study was polypropylene because of its large use and the need to recycle it with the maintaining of good aspect properties.

The effects of four factors known to influence injection conditions, material temperature, mold temperature, injection flow and number of injection cycles were studied using a statistical approach. The three variables (materiel temperature, mold temperature and injection flow) were investigated at three industrial used levels (materiel temperature: $220,240,260{ }^{\circ} \mathrm{C}$, mold temperature: $30,50,80{ }^{\circ} \mathrm{C}$ and injection flow: 10 , $20,40 \mathrm{~cm}^{3} / \mathrm{s}$ ). The number of recycling varies from cycle 0 to cycle 4 at five levels. The complete matrix for screening was designed using D-optimal quadratic design. The experimental design was generated with the statistical software MODDE 10.1Umetrics. A set of 45 experiments was carried out to determine the influence of injection parameters and recycling on the appearance properties of samples. The statistical software package $\mathrm{Nemrodw}^{\circledR}$ version 2007, LPRAI (Marseille, France) was used to analyze the experimental design.

The response approach involving a D-optimal quadratic design was adopted for studied the effect of injection parameters and recycling on the final response (colorimetric and gloss). In fact, A D-optimal quadratic design is a computer aided design which contains the best subset of all possible experiments. Depending on a selected criterion and a given number of design runs, the best design is created by a selection process.

Each variable (material temperature, mold temperature, injection rate) was studied at three different levels (1,2, and 3). The four recycling cycles was studied with four levels $(1,2,3$, and 4). All variables were taken at a central coded value of zero. The set of levels of the variables is summarized in Table 1.

Table 1 D-optimal plan variables used in the area of interest (Design of Experiments-DOE)

\begin{tabular}{|c|c|c|c|c|}
\hline \multirow{2}{*}{$\begin{array}{l}\text { Type de variable } \\
\text { Discrete block }\end{array}$} & \multirow{2}{*}{\begin{tabular}{|l} 
Name(Pi) \\
Number of cycle
\end{tabular}} & \multicolumn{3}{|c|}{ Value } \\
\hline & & 0 & & \\
\hline & & 1 & & \\
\hline & & 2 & & \\
\hline & & 3 & & \\
\hline & & 4 & & \\
\hline \multirow[t]{3}{*}{ Continue } & T material $\left({ }^{\circ} \mathrm{C}\right)$ & 220 & 240 & 260 \\
\hline & Tmold $\left({ }^{\circ} \mathrm{C}\right)$ & 30 & 50 & 80 \\
\hline & Injection rate $\left(\mathrm{cm}^{3} / \mathrm{s}\right)$ & 10 & 20 & 40 \\
\hline
\end{tabular}


Each variable was coded between -1 and 1 according to Eq. (1):

$$
X_{i}=2 \frac{P_{i}-\frac{P_{i \max }+P_{i \min }}{2}}{P_{i \max }-P_{i \min }}=2 \frac{P_{i}-\overline{P_{i}}}{\Delta P_{i}}
$$

with $P_{i}$, the variable to be coded between $\mathrm{P}_{\text {imin }}$ and $\mathrm{P}_{\text {imax }}$ respectively corresponding to the minimum and maximum of the experimental variables. The use of reduced centered variables has the advantage of being able to generalize the theory of the experiments plans whatever the factors or the fields of studies retained.

The responses have been adapted in order to know the final evolution of the colorimetric and brightness parameters according to the quadratic D-optimal model described above and corresponding to Eq. (2).

The minimum and maximum range of variables investigated and the full experimental plan with respect to their actual and coded forms. The analysis of the data was carried out to obtain an empirical model defining the response $\mathrm{Y}$ (Eq 1), which is the value of colorimetric ( $\left.\mathrm{L}^{*}, \mathrm{a}^{*}, \mathrm{~b}^{*}\right)$ or gloss (R20, R60, R85).

$$
\begin{aligned}
Y= & b_{0}+b_{1 A} \cdot X_{1 A}+b_{1 B} \cdot X_{1 B}+b_{2 A} \cdot X_{2 A}+b_{2 B} \cdot X_{2 B}+b_{3 A} \cdot X_{3 A} \\
& +b_{3 B} \cdot X_{3 B}+b_{4 A} \cdot X_{4 A}+b_{4 B} \cdot X_{4 B}+b_{4 C} \cdot X_{4 C}+b_{4 D} \cdot X_{4 D}
\end{aligned}
$$

$\mathrm{Yi}$ was the responses in terms of colorimetry and brightness. This result was of three separate tests and reflect the colorimetry values $\mathrm{L}^{*}, \mathrm{a}^{*}, \mathrm{~b}^{*}$ and brightness respectively at angles $\mathrm{R} 20, \mathrm{R} 60$, and $\mathrm{R} 85$.

\section{Results and Discussion}

Results in terms of gloss and colorimetric responses are analyzed with the statistical software package Nemrodw-version 2007, LPRAI (Marseille, France) and shown respectively in Figs. 2 and 3. The reference is taken on the value of the highest level (black bar). The influence of the injection temperature $\left(220,240\right.$ and $\left.260{ }^{\circ} \mathrm{C}\right)$, the mold temperature $\left(30,50\right.$ and $\left.80{ }^{\circ} \mathrm{C}\right)$, the injection rate $\left(10,20\right.$ and $\left.40 \mathrm{~cm}^{3} / \mathrm{s}\right)$ and the number of injection cycle (cycle 0 to cycle 5) on the gloss of different PP samples with smooth surface is shown in Fig. 2.

Figure 3 shows the effect of varying injection parameters and number of cycles on gloss (R20, R60, and R85). It can be observed that the recycling number change the gloss properties by varying R20, R60 and R85. These variations are not in the same way because of recycling lead to a decrease in R20 and an increase in R60 and R85. The effect of material temperature is observed only for R20 (Fig. 2a) for which the increase in material temperature lead to a decrease in R20. The modification of the mold temperature leads to variations in R20 and R60. The increase in mold temperature leads to an increase in R20 and R60. The interaction between the effect of material temperature and mold temperature lead to the increase of $\mathrm{R} 20$ at $80{ }^{\circ} \mathrm{C}$ of mold temperature. The injection rate does not significantly affect the gloss properties. In general, the number of injection cycles and the mold temperature has the greatest effect on the gloss level. For colorimetric response (Fig. 3) we have the same important effect 
(a)
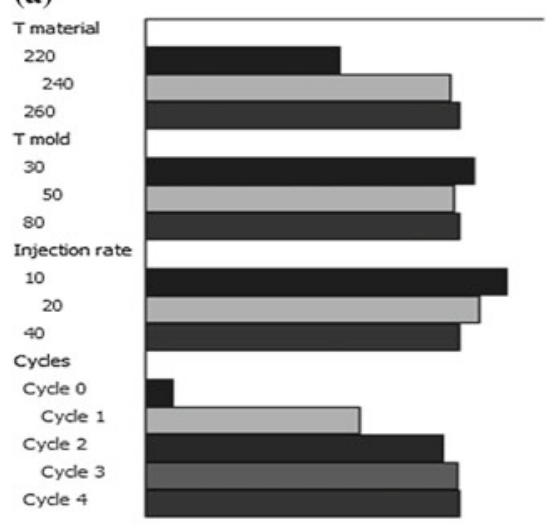

(b)

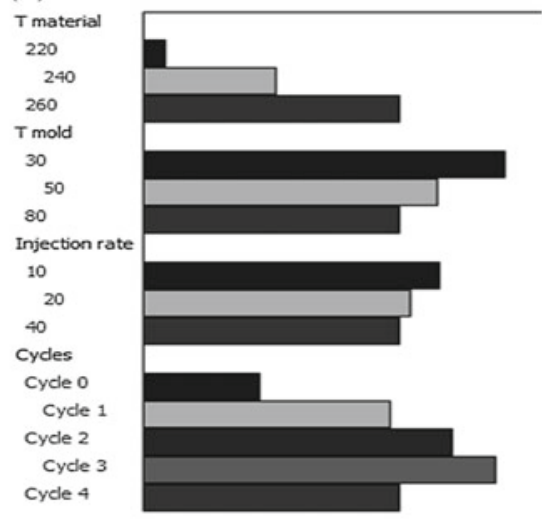

(c)

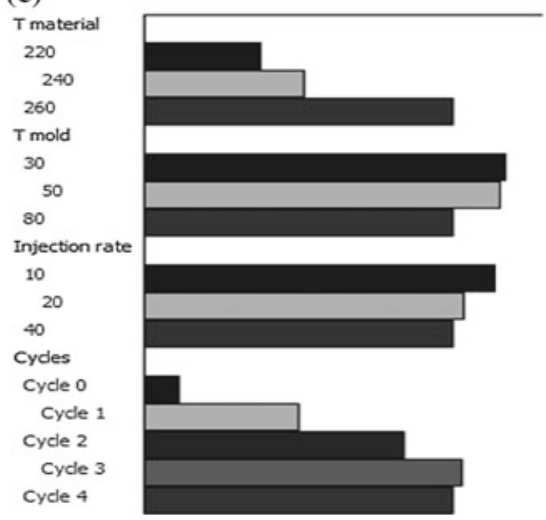

Fig. 3 Graphic representation of the difference in weight of the factors on total effect for the colorimetric response $\mathbf{a} \mathrm{L}^{*}, \mathbf{b} \mathrm{a}^{*}, \mathbf{c} \mathrm{b}^{*}$

of the recycling and the material temperature on $\left(\mathrm{L}^{*}, \mathrm{a}^{*}, \mathrm{~b}^{*}\right)$ that increases with increasing the number of cycles and the material temperature. The effect of mold temperature and injection rate is opposite and leads to a decrease in $\left(L^{*}, a^{*}, b^{*}\right)$.

We can note that colorimetric and a gloss property depends on changes in injection conditions and number of recycling cycles. The recycling and material temperature have the most important effect on colorimetric. The variations of gloss are obtained by changing the number of cycles, the material temperature and the mold temperature. Table 2 illustrate the pareto effect of all parameters. So, we notice that the numbers in bold highlighted the most important effect on gloss measurements. The studies of the appearance properties of the injection molded samples revealed that changes in injection parameters and number of cycles had a significant influence on colorimetric and gloss. Generally, appearance properties are related to the surface roughness. The differences in optical and appearance properties between samples were presumed to arise from the variation in the surface topography in according to the literature. 
Table 2 The effect of injection parameters and number of cycles on the colorimetric and specular gloss measurements (Pareto individual effect from response analyses with Nemrodw)

\begin{tabular}{l|c|c|c|c|c|c}
\hline & $\mathrm{L}^{*}$ & $\mathrm{a}^{*}$ & $\mathrm{~b}^{*}$ & $\mathrm{R} 20$ & $\mathrm{R} 60$ & $\mathrm{R} 85$ \\
\hline Cycle $0 / 4$ & $\mathbf{7 1}$ & 14 & $\mathbf{4 0}$ & 8 & $\mathbf{3 8}$ & $\mathbf{5 8}$ \\
\hline Cycle $1 / 4$ & 9 & 0 & 14 & 11 & 0 & 20 \\
\hline Cycle $2 / 4$ & 0 & 2 & 1 & 5 & 0 & 3 \\
\hline Cycle 3/4 & 0 & 7 & 0 & 0 & 5 & 5 \\
\hline $\mathrm{T}_{\text {mat }} 220 / 260$ & 16 & $\mathbf{5 0}$ & 26 & $\mathbf{3 2}$ & 0 & 0 \\
\hline $\mathrm{T}_{\text {mat }} 240 / 260$ & 0 & 13 & 15 & 0 & 0 & 2 \\
\hline $\mathrm{T}_{\text {mold }} 30 / 80$ & 0 & 11 & 2 & 0 & $\mathbf{4 7}$ & 3 \\
\hline $\mathrm{T}_{\text {mold }} 50 / 80$ & 0 & 1 & 0 & $\mathbf{3 2}$ & 7 & 2 \\
\hline Flow $10 / 40$ & 2 & 1 & 0 & 1 & 0 & 7 \\
\hline Flow 20/40 & 0 & 0 & 0 & 8 & 3 & 0 \\
\hline
\end{tabular}

\section{Conclusion}

The optical properties of recycled parts can be maintained during numerous internal recycling. The variations of properties are in the same range that is observed by changing processing parameters. The recycling and the material temperature are the most important factors changing the colorimetric properties of the material. The mold temperature affects only the gloss and there is no change in properties by varying the injecting flow. Also, aspect properties of recycled parts can be maintained during numerous internal recycling up to three cycles.

\section{References}

1. Allen NS, Hardy SJ, Jacobine AF, Glaser DM, Yang B, Wolf D, Catalina F, Navaratnam S, Parsons BJ (1991) Photochemistry and photopolymerization activity of perester derivatives of benzophenone. J Appl Poly Sci 42:1451

2. Baccouch Z, Mbarek S, Jaziri M (2017) Experimental investigation of the effects of a compatibilizing agent on the properties of a recycled poly(ethylene terephthalate)/ polypropylene blend. Polym Bull 74:839

3. Moore EP (1996) Polypropylene handbook: polymerization, characterization, properties, processing, applications. Hanser, Munich, Germany

4. Vilaplana F, Karlsson S (2008) Quality concepts for the improved use of recycled polymeric materials: a review. Macromol Mater Eng 293:274

5. Tredoux L, Satoh I, Kurosaki Y (1999) Investigation of wave-like flow marks in injection molding: flow visualization and micro-geometry. Polym Eng Sci 39:2233-2241

6. Yoshii M, Kuramoto H, Kawana T (1996) The observation and origin of micro flow marks in the precision injection molding of polycarbonate. Polym Eng Sci 36:819-826

7. Fellahi S, Meddad A, Fisa B, Favis BD (1995) Weldlines in injection-molded parts: a review. Adv Polym Technol 14:169-195 
8. Xie L, Ziegmann G (2008) A visual mold with variotherm system for weld line study in micro injection molding. Microsyst Technol Micro-Nanosyst-Inform Storage Process Syst 14:809-814

9. Lee J, Turng LS (2010) Improving surface quality of microcellular injection molded parts through mold surface temperature manipulation with thin film insulation. Polym Eng Sci 50:1281-1289

10. Liu SJ, Chang JH (2000) The occurrence of surface roughness in gas assist injection molded nylon composites. Polym Composite 21:322-331

11. Oliveira MJ, Brito AM, Costa MC, Costa MF (2006) "Gloss and surface topography of abs: a study on the influence of the injection molding parameters. Polym Eng Sci 46:1394-1401

12. Theilade UA, Hansen HN (2007) Surface microstructure replication in injection molding. Int J Adv Manuf Technol 33:157-166

13. Zhang A, Zhao G Guan Y (2015) Effects of mold cavity temperature on surface quality and mechanical properties of nanoparticle-filled polymer in rapid heat cycle molding. J Appl Polym Sci

14. Dawkins E, Engelmann P, Horton K, Monfore M (1998) Color and gloss-the connection to process conditions J Inject Mold Technol 1:1

15. Hunter RS, Harold RW (1987) The Measurement of appearance. Wiley, New York

16. Withehouse DJ, Bowen DK, Venkatesh VC, Lonardo P, Brown CA (1994) Cirp annals 43:541

17. Donald B, Mathew R (1988) SPE Antec Tech Paper 34:18

18. Huff K (1994) Visual assessment and practical colorimetry in the plastic industry. Bayer AG, Leverkusen, Germany

19. Dalal EN, Natale-Hoffman KM (1999) The effect of gloss on color. Color Res Appl 24:369

20. Wang L, Huang T, Kamal MR, Rey AD, Teh J (2000) Surface topography and gloss of polyolefin blown films. Polym Eng Sci 40:747-760

21. Lange Dr (1981) Color difference measuring instrument. Micro color, operating instructions, 4 edn. BDA 163

22. ISO 2813 (1994) Paints and varnishes. Measurement of specular gloss of nonmetallic paint films at 20_,60_ and 85 _ 